\title{
Editorial
}

\section{Improving outcomes of medical colleges: Institutional Governance and Communication Protocol (IGCP)}

\author{
Ghanim Alsheikh ${ }^{1^{*}}$ \\ ${ }^{1}$ WHO Collaborating Centre for Public Health Education and Training, Imperial College London, UK.
}

\begin{abstract}
Received: 10.04 .2020
Accepted: 23.04 .2020

Abstract

Governance and communication represent the foundations for effective impact on the level of institutional performance in higher education colleges, including medical schools. Governance encompasses the frameworks of structures, relationships, and processes ongoing in the college. It is recognized that medical schools in Iraq lack the adoption of a clear mechanism in this field. This article aims to present a proposed protocol for the development of governance and institutional communication in Iraqi medical colleges whose components have been formulated according to the needs of these colleges. The proposal reviews the components, benefits, and foundations of governance according to a number of targeted values, thus presenting a proposed framework for the components of an institutional system for governance and communication. This proposal allows ample discussions among college stakeholders which leads to revision and implementation to fill the gap towards achieving effective and efficient governance that enables the achievement of college goals. The framework addresses number of elements including at least: neutrality in the work and decisions of councils and their strategic and operational roles, the absence of a strategy for senior management, institutional and individual periodic planning, standard operation procedures, job description, key performance indicators, human resource management policies and documentation concepts, and in the forefront of them digital documentation and communication via the Internet and databases.
\end{abstract}

Keywords Medical colleges, Governance, Communication, Iraq

*Correspondence to Ghanim Alsheikh, WHO Collaborating Centre for Public Health Education and Training, Imperial College London, UK.

$\triangle \quad$ alsheikhg@gmail.com

Compliance with ethical standards Conflict of interest the authors declare no conflict of interest

$\mathrm{G}$ overnance encompasses the structures, relationships and processes through which policies for institutions are developed, implemented and reviewed. Governance is a key determinant of growth, advancement and overall development of any establishment, and indeed any medical college. Organisation and governance in higher education is one of the primary teaching and research references in the study and practice of post-secondary education. Research in higher education has provided new insights and recommendations for the management of post-secondary institutions. ${ }^{[1]}$ Governance of the college is the least well-understood aspect of the academic life in medical colleges. The importance of governance is more emphasized when a change of curriculum is intended or practiced and becomes fundamentally vital and pivotal for the success of the change plan. ${ }^{2]}$ Academic governance is the framework of policies, structures, relationships, systems and processes that collectively provide leadership to and oversight of a higher education provider's academic activities (teaching, learning and scholarship, and research and research training, community service) at an institutional level. ${ }^{[3]}$

The Organisation for Economic Cooperation and Development (OECD) presents the following five core functions of effective governance: (a) to ensure clarity of 
the college's vision, mission and strategic direction; (b) to hold the decision-makers accountable against standards and benchmarks through their plans; (c) to ensure soundness and correctness; (d) to ensure leadership complies with rules and regulations, and (e) to engage all the college stakeholders. $^{[4]}$ To ensure achieving these functions, they need to be accompanied with more focused micro-governance in regard to availability of the right information, the appropriate incentives, the timely and right interventions, and the continuous quality improvement and innovations.

No doubt, governance needs to employ the appropriate implications of local systems and environments in different countries in compliance with standardised general principles and strategies for an effective governance. As related to the medical colleges in Iraq and their situation and environment, we identified the following players who will be beneficial on both sides of the presented equations with the processes of the right governance:

- Role of the dean, assistant deans and heads of departments vs. the rest of staff, students and other stakeholders.

- Role of actors in governance and management in being static vs. dynamic.

- Smooth cooperative attitude vs. lack of harmony and weak performance.

- College-wide participation vs. segregated awareness and activities.

Governance of Iraqi medical college functions are neither planned for nor assessed systematically. This proposed "Institutional Governance and Communication ProtocolIGCP" needs to be thoroughly studied, discussed and revised before endorsing the final version and making it known to all stakeholders both present and new comers in future. The protocol aims at creating better environment, effectiveness and efficiency in leadership and management towards a college-wide participation to improve the college environment and outcomes. The protocol considers improving at least the following 10 values and principles that symbolise the work at the college:

1. Equality and fairness

2. Intelligence and information

3. Strategic vision and planning

4. Equity and inclusiveness

5. Transparency

6. Responsiveness

7. Participation and consensus orientation

8. Ethics

9. Effectiveness and efficiency

10. Accountability

In order to facilitate achieving the above positive and constructive atmosphere in any of the 29 Iraqi medical colleges that exist today, the following measures need to be planned for, introduced, implemented and systematically monitored with effective actions to correct unexpected divergence and deviation. Whenever needed, these measures can be updated, amended or new measures added to better serve the purpose of this Protocol and the aims of the college. Each measure needs to be activated by formal and appropriate orders from the college or university. It is assumed that the implementation of all these measures need no extra financial burden. The investment of the college in implementing the protocol needs good planning and sound follow up, monitoring and evaluation to ensure achievement of the expected results and initiation of corrective actions based on regular feedback. The improvement of governance plays an overarching effect to improve the college's compliance with all standards and domains set out to achieve quality improvement and accreditation. The 
Medical College Institutional Governance and Communication Protocol covers the following domains:

\section{Impartiality of College Council (CC) Judgment and Decisions}

Because all members of the $\mathrm{CC}$ are also the main players involved in the daily management of the college, the $\mathrm{CC}$ is unlikely to be impartial. Having balanced representation of non-executive independent members will help avoid prejudice and conflicts of interest between the CC and the college population and stakeholders. Independent judgment is almost always in the best interest of the college. Considerable number of representatives from all stakeholders need to be added to the membership of the CC or at least be invited to attend $\mathrm{CC}$ meetings on relevant agenda items.

\section{Extended College Board or Assembly (ECB/A)}

An advisory ECB/A should be established to include all staff (full and part time academic staff, health office trainers, junior demonstrators and interns, administrative and support staff) and adequate balanced representation of students (e.g. 5-10 representative from each class). ECB meets at least once or twice a year to discuss the annual report prepared by management and approved by CC with clear achievements and failures of the college. The suggestions and proposals of the ECB will be considered by the $\mathrm{CC}$ and management in the next year's annual plan and revisited during the next ECB meeting. All meetings should have an agenda proposed by any of its members and should be circulated well ahead of the time of the meeting.

\section{Strategic Role and Operator Role}

College Council should play the main role in the strategic planning and as advised by the ECB. This role should be balanced with, separated from attending to the "day-today" operational duties. Working groups and task forces/committees should be the mechanism to achieve this $\mathrm{CC}$ role with clearly defined, specified and detailed timebound terms of reference for each group and task force.

\section{An Exit Strategy for College Officers}

All posts should be assigned to run for certain known period/s at least for planning purposes and that each post holder make a strategic plan for the period and operational annual plans to run throughout the prescribed period/s. Exit strategy for all amendments will be based on evidence and according to evolving needs, and $\mathrm{CC}$ should determine whether it is a succession plan for passing on a family business or a buy-sell arrangement. An exit strategy should be planned and agreed upon by all parties concerned (e.g. stakeholders, both internal and external) well in advance.

\section{Annual Plans and Reports}

Dean, Vice-Deans and Heads of Departments will prepare and submit annual plans and annual reports before and after each academic year. Plan is prepared before start of each academic year, setting expected results at end of the year, and report is prepared after measuring and assessing these results at the end of each academic year. The plans and reports will be discussed by the ECB and endorsed by CC and communicated to university and made publicly available for institutional stakeholders and online. Plans should include all strategic and operational development elements and quality improvement measures that would be executed during the relevant year with clear measurable indicators. Accordingly, annual reports measure the indicators stated in the plan and identify failure to accomplish any 
with reasons. The Dean's annual plan and report will integrate and incorporate (not copy and paste) all plans and reports prepared by Vice-deans and Heads of Departments to meet the college's strategy. Integration of these plans and reports to produce "new amalgamated" institutional plan and report for every academic year which serve to measure institutional outcomes. Institutional outcomes cover all results expected in plan and measured/assessed in report. All plans and reports should include well defined "what-how-who-when-cost if any" items for all activities. Accountability at its highest scale is to be considered accordingly.

\section{Standard Operation Procedures (SOP)}

The college potential stakeholders feel more confident if they know that the college has reliable systems and procedures in place. Such processes enable staff and students to operate in the day-to-day work when concerned management is absent and which allows for smooth handovers to other parties. All procedures should be well described and made known to operators and users alike. Procedure is a set of actions and that is agreed upon to be the official way of doing a prescribed process and practice. The college must have approved such procedures and all operators must follow the correct procedure at all times. The college should start to introduce one or few procedures and work towards adding more. Procedures can be updated and improved as use yields feedback but any change should be approved by the college.

\section{Job Description (JD)}

Job description (JD) is needed for all employees according to a balanced demand and availability of staff. The JD should be shared with and made known to both employees and direct supervisors and clients like students and staff in all departments and units. The JD should be updated to respond to evolving development and changes in structure, functions and procedures.

\section{Individual development plans (IDP)}

Every employee in the college, junior and senior, need to prepare her/his IDP at the beginning of a target period. This period could vary from a single academic year to a period of more than one year but a sound and active college should think of annual IDP. IDP is necessary to keep each employee up to today's fast-paced college needs from each in order to collectively work to achieve the college aims. Supervisors should review and approve their employees plans at the appropriate level of management and at the end of the plan period assess each IDP. At its core, an IDP is a simple one- to two-page document that sums up the employee's current job and job goals. The relevant management should work to fulfil the needs of the IDPs and stated in supervisor's plans. The exact outline can be different for everyone, but each IDP should contain few key elements: ${ }^{\text {[5] }}$

- A list of critical skills, knowledge, and abilities as related to current job.

- A list of employee's key weaknesses/development needs as related to current job.

- A list of employee's short and longterm goals to fulfil above development needs.

- An outline of employee's developmental objectives and what is needed to do to reach own goals.

- A list of the appropriate strategies to use to achieve own objectives.

\section{Key performance indicators}

These indicators (included in college and departments plans) are used for measuring the performance of the pertinent 
unit, its management and even the college council.

\section{Remuneration and Human Resources policies}

Transparency, in matters such as remuneration, incentives, discipline and dismissal, is essential for motivating and attracting good employees. It is especially important for retaining efficient staff and encouraging others. Remuneration (financial and non-financial) should be made known with clear description of the reason behind it to encourage others. This includes all stakeholders and particularly students to enhance the process of learning as well as non-curricular participation.

\section{Documentation}

It is of utmost importance that documentation is given top priority in this effort to improve governance. The inward and outward correspondence and receipt and issuance of orders should be formal with clear serial numbering that relates to a main registry book for the college Dean's office. Departments (single or cluster) should keep their own book of registry for internal (their staff) and external within and outside college as per delegation and job descriptions. It is the responsibility of the Dean and ViceDeans to keep such system flowing and sustainable. This means all in and out flow, not only administrative material but necessarily cover scientific, personal, academic and most important meetings' agendas and minutes. No doubt, a transfer to the use of the fast developing and expanding online documentation and communication should be a top priority for any effective governance and communication strategy.

\section{References}

1. Brown MC, Lane JE, Zamani-Gullaher EM. Organization and Governance in Higher Education. Nottingham: Pearson Learning Solutions. 2010. ISBN: 0558849520.

2. Bland CJ, Starnaman S, Wersal L, Moorehead-Rosenberg L, Zonia S, Henry R. Curricular change in medical schools: how to succeed. Academic medicine. 2000; 75(6):575-594.

3. Australian Universities Quality Agency. Academic governance and quality assurance. Sydney: AUQA Occasional Publication. 2010. Accessed 31/03/2020:

https://www.teqsa.gov.au/latestnews/publications/guidance-note-academicgovernance

4. Hénard F, Mitterle A. Governance and quality guidelines in Higher Education. Paris: OECD Online Bookshop. Accessed 31/03/2020:

http://www.oecd.org/education/imhe/460644 61.pdf

5. University of California San Diego. Your Individual Development Plan. Accessed 31/03/2020: https://blink.ucsd.edu/HR/training/IDP.html 


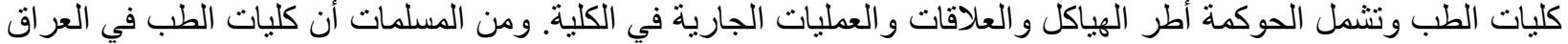

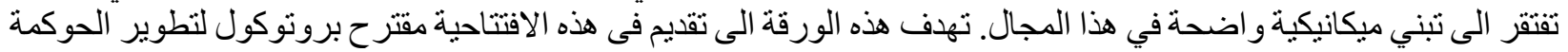

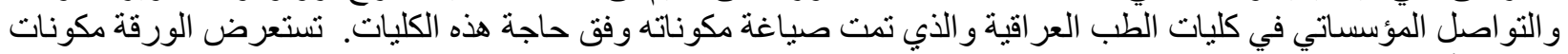

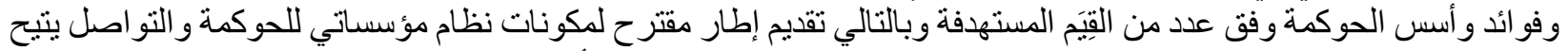

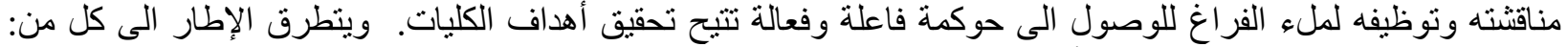

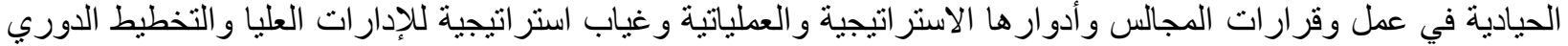

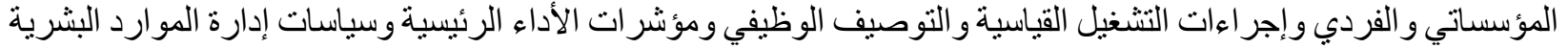
ومفاهيم التوثيق وفي المقدمة منها التوثيق و التو اصل الرقئ التمي عبر شبكة الانترنت وقو اعد البيانات. 